OXford, A. E. (1951). J. gen Microbiol. 5, 83-90.

\title{
The Conversion of Certain Soluble Sugars to a Glucosan by Holotrich Giliates in the Rumen of Sheep
}

\author{
By A. E. OXFORD \\ The Rowett Research Institute, Bucksburn, Aberdeenshire
}

\begin{abstract}
SUMMARY: When in vitro fermentations of glucose, fructose or sucrose are carried out under conditions comparable with those in the rumen by means of relatively small inocula of strained rumen contents from hay-fed sheep, the holotrichously ciliated protozoa which are present store immense numbers of microscopic granules consisting of a practically protein-free glucosan giving a purple colour with iodine. The granules can be liberated by bursting the protozoa by the action of the synthetic detergent Teepol XL under mild conditions. An exactly similar polysaccharide granule preparation can be made from protozoa present in the rumen itself if rumen contents are withdrawn 2-4 hr. after feeding. The yield of iodophilic polysaccharide so obtained may be equivalent to approximately $25 \%$ of the weight of water-soluble, yeast-fermentable sugars in a single feed of hay. No granule-filled protozoa are present $9 \mathrm{hr}$. after feeding.

Other simple sugars such as glucuronolactone, galactose, mannose, xylose, arabinose, sorbose, lactose, cellobiose and maltose, are not markedly converted into polysaccharide granules by rumen protozoa, during in vitro fermentation.
\end{abstract}

The most obvious group of micro-organisms ordinarily inhabiting the rumen of sheep are the large ciliated protozoa. Bulk for bulk, although of course not numerically, they usually exceed the bacterial population (Mangold, 1929). Nevertheless, they appear not to be entirely essential for the adequate functioning of at least some rumen fermentations, since defaunated sheep have been shown to continue to thrive (van der Wath \& Myburgh, 1941; Johnson, Hamilton, Robinson \& Garey, 1944). The current view is therefore, not unnaturally, that the protozoa, from the point of view of fermentation reactions, are of minor importance when compared with the rumen bacteria (see Elsden \& Phillipson, 1948). A very simple experiment (recorded later) having disproved this extreme view in one particular instance, namely glucose fermentation by the rumen contents of hay-fed sheep, it became of interest to find out the action of rumen protozoa on fermentable sugars. No claim is here made that protozoa are important in all rumen fermentations. This paper is mainly concerned with the storage of polysaccharide granules during carbohydrate fermentation by one important group of protozoa - the holotrichously ciliatedusually present in the sheep's rumen.

\section{METHODS}

Animals. Rumen contents were obtained as required from two Suffolk-cross ewes, Sheep 272 and $\mathbf{3 3 7}$, aged $2 \frac{1}{2}$ years, fitted with permanent rumen fistulae by Dr J. Tosic (1949). They had been fed exclusively on good-quality starchfree meadow hay, containing about $14 \%$ of water-soluble constituents of which about one-seventh was yeast-fermentable carbohydrate (probably fructose), for several months before the experiments. Their weights had been well main- 
tained during this period. Each was fed at $12 \mathrm{hr}$. intervals with 800-900 g. hay; nearly all the food was consumed within $1 \mathrm{hr}$. Sheep 272 was chiefly used but 337 gave similar results whenever its rumen contents were used in parallel experiments.

In vitro fermentation of simple sugars by rumen contents. The method was essentially that of Elsden (1946) for glucose, with small Buchner flasks as fermentation vessels; in order to quicken the fermentation the inoculum of strained rumen-liquor was usually increased from 10 to $17 \%(\mathrm{v} / \mathrm{v})$, an extra buffering agent in the form of sodium acetate $(0.5 \%)$ was added (this is permissible because rumen contents always contain this salt), and the saturation with $\mathrm{CO}_{2}$ from an external source was omitted. The same end was achieved more quickly by adding the requisite amount of glacial acetic acid, last of all to the buffer mixture containing bicarbonate, arranging matters so that after the addition of the inoculum the Buchner fermentation flask was full to the sidearm. The final concentration of sugar was always $0.9 \%$ or less and the $\mathrm{pH}$ value at the beginning of the fermentation was $6 \cdot 8-7 \cdot 0$. The fermentation flasks were shaken from time to time.

This simple fermentation system was used to demonstrate that the true fermentative action of protozoa was on occasion at least of the same order of magnitude as that of rumen bacteria. Muslin-strained rumen contents (500 ml.; see below) taken $3 \mathrm{hr}$. after feeding was allowed to stand for $1 \mathrm{hr}$. at $40^{\circ}$ in a tall beaker covered with a clock glass. The supernatant liquor was then carefully decanted from the bottom protozoan layer, the latter was washed twice by decantation with the Elsden buffer $(50 \mathrm{ml}$.) to remove most of the free bacteria, and then made up to $20 \mathrm{ml}$. Fermentations with $10 \mathrm{ml}$. of the final protozoan suspension and $30 \mathrm{ml}$. of the first rumen supernatant (rich in bacteria but still containing some protozoa) were run side by side, each fermentative liquid containing initially $0.4 \%$ glucose. The $\mathrm{pH} 7$ buffer used in each case to make up the reaction volume to $100 \mathrm{ml}$. was prepared with sodium carbonate (not bicarbonate) and acetic acid; the medium was then not supersaturated with $\mathrm{CO}_{2}$ at the start. The gases evolved during the fermentations were collected over warm water. After $4 \mathrm{hr}$. at $40^{\circ}$ the protozoan fermentation had evolved two and a half times as much gas $(22 \mathrm{ml}$.) as the (mainly) bacterial fermentation $(9 \mathrm{ml}$.). It must be remembered that the protozoan fermentation was due to the large organisms from some $250 \mathrm{ml}$. of rumen liquor, as against $30 \mathrm{ml}$. for the bacterial fermentation; on the other hand, the so-called 'bacterial' fermentation was partly due to small protozoa which did not sediment readily. There was, in fact, a distinct layer of protozoa on the bottom after $4 \mathrm{hr}$.

Separation of the larger protozoa from rumen contents or from in vitro fermentation liquids. The method of straining through six layers of surgical gauze without squeezing allowed surprisingly little plant debris through into the filtrate, but in order to collect the greater part of the larger protozoa it was necessary to scrape the deposit from the gauze, resuspend it in distilled water and re-strain through clean gauze. The combined filtrates were then stood for at least $1 \mathrm{hr}$. in boiling-tubes filled to the top, when the larger, whiter, and heavier protozoa gradually sank to the bottom. The supernatant was carefully decanted, the 
deposit washed several times by decantation with $0.003 \mathrm{~m}$ phosphate buffer (pH 6.8) and finally with distilled water. The final deposits contained relatively very few free bacteria and consisted almost entirely of protozoa together with a very little plant material. As will be seen from the results reported, many fermentation liquids contained polysaccharide-filled protozoa which were very easily and quickly washed clean by the above simple method, because they settled rapidly under the influence of gravity, being much more dense than their unfilled fellows or than water or rumen liquor itself.

Liberation of the granules from washed protozoa. This was readily achieved with the holotrichs by incubation at $39^{\circ}$ for $1-2 \mathrm{hr}$., with occasional shaking, in about one-tenth of the original rumen liquor volume of a solution of Teepol XL $(0.2 \%)$ in $0.003 \mathrm{M}$ phosphate buffer ( $\mathrm{pH} \mathrm{6.8)}$. (Teepol XL; British Drug Houses Ltd. is sold as a powder giving an almost neutral solution in water and is said to be the sodium salt of a secondary alkyl sulphate.) The tube was then allowed to stand at room temperature for 1-2 hr. until most of the protozoan debris and unburst protozoa of other genera had settled to the bottom as a greyish deposit below a milky supernatant liquor. The latter, which on examination with the high dry objective was seen to consist almost entirely of a suspension of tiny granules, was carefully decanted and the granules therein collected by centrifuging. The deposit was twice resuspended in water, separated by decantation and finally collected and dried in vacuo over concentrated $\mathrm{H}_{2} \mathrm{SO}_{4}$ at $39^{\circ}$ for several days. The dried preparations were analysed for total nitrogen (micro-Kjeldahl) and for reducing sugar by Neish's (1946) modification of the Shaffer-Somogyi method after hydrolysis with $0.55 \mathrm{~N}-\mathrm{HCl}$ at $100^{\circ}$ for $2 \mathrm{hr}$., followed by neutralization with $\mathrm{N}-\mathrm{NaOH}$. In certain instances the alkaline iodine method of Hinton \& Macara (1924), under conditions applicable to aldose sugar only, was also used. No attempt was made to determine the carbohydrate content of preparations containing more than $2 \% \mathrm{~N}$.

\section{RESULTS}

Storage of iodophilic granules in protozoa during in vitro fermentations with a small inoculum of rumen liquor

The only simple sugars with which a visible fermentation began within 1-3 hr., when the inoculum was derived from rumen liquor in its most active state (viz. 2-4 hr. after feeding of the sheep), were glucose, fructose, sucrose, galactose and xylose. With arabinose, mannose, cellobiose, lactose, maltose, glucuronolactone and soluble starch, there was a longer delay before gas evolution was observed. With sorbose, or with no added sugar at all, no obvious fermentation took place. In the case of the first three sugars listed a conspicuous, pure white, sandy layer of protozoa had settled to the bottom of the fermentation vessel within $3 \mathrm{hr}$., and this heavy white layer persisted apparently unchanged even after $24 \mathrm{hr}$. provided that the initial sugar concentration was not too great. It could then easily be collected, washed by decantation, and thus separated from a much less dense and more flocculent greyish green layer situated above it. The bottom white layer consisted mostly of large holotrichs, together with some equally 
large oligotrichously ciliated protozoa (Diplodinium, etc.). Every one stained solidly brownish purple with iodine. The more flocculent greyish green layer contained representatives of both groups, sometimes individually iodophilic, together with clumps of bacteria and some plant debris. A similar bottom layer was obtained with the other fermentable sugars, but iodophilic protozoa were not especially in evidence therein, and indeed, with xylose, almost entirely absent. The action of Teepol XL upon the heavy white protozoan bottom layer was to cause nearly all the iodophilic holotrichs to burst, thereby liberating an uncountable number of discrete granules from each ruptured organism. These granules stained intensely purple-brown with iodine; leaving the protozoan cases and macro-nuclei, often distorted in shape, stained only a yellowish brown. The granules varied in size from that of large cocci to small yeasts, and were of an assortment of shapes, chiefly elliptical or roughly circular. A few much larger pseudo-crystalline particles were also seen, usually five or six-sided. These were apparently not derived from the holotrich ciliates but from the rare bursting of smaller oligotrich ciliates. If a wet preparation was made by mixing one drop of the milky granule suspension with one drop of Loeffler's methylene blue, the protozoan debris took the stain whereas the granules did not. Likewise, if a heat-fixed preparation was stained, the granules were found not to take any of the ordinary bacterial stains.

The inference that the granules were almost entirely polysaccharide in nature was confirmed by analysis of the various dried preparations made from in vitro fermentations. The results are shown in Table 1 which also includes some analyses carried out on the protozoan granule preparations made from strained rumen liquor itself, taken 2-3 hr. after feeding of the sheep. The purification by washing of the iodophilic protozoa was somewhat more difficult in these latter experiments, but relatively protein-free granule preparations could nevertheless be obtained. The results in Table 1 further show clearly that a synthesis of protozoan polysaccharide granules must have taken place in the in vitro sugar fermentations. This conclusion was supported by a comparative microscopic examination of iodine-stained wet preparations, when it was seen that the washed protozoa from in vitro fermentations were on the average much whiter, larger and stained more solidly, than those present in the rumenliquor used as inoculum.

\section{Influence of 'age' of inoculum on the in vitro synthesis of polysaccharide granules}

By 'age' of inoculum is meant here the time in hours between the feeding of the sheep and the withdrawal of the rumen-liquor through the fistula. Sheep 272 was used for an experiment in which the various 'ages' were $2,4,6.5$, and $9 \mathrm{hr}$. Fermentations were carried out in each instance upon fructose in vitro using the customary $17 \%(\mathrm{v} / \mathrm{v})$ inoculum of strained rumen-liquor. After $24 \mathrm{hr}$. all the fermentation liquors contained a copious white bottom layer of iodophilic protozoa which was easily washed, by decantation, with distilled water. Holotrichs predominated in all save in that from the $9 \mathrm{hr}$. inoculum where the iodophilic oligotrichs perhaps predominated. The nitrogen content of 
Table 1. Analysis of dried protozoan preparations obtained from rumen liquor and sugar fermentations therewith

(All results are calculated for an inoculum of $100 \mathrm{ml}$. of rumen liquor; fermentation period with sugars, $20 \mathrm{hr}$.)

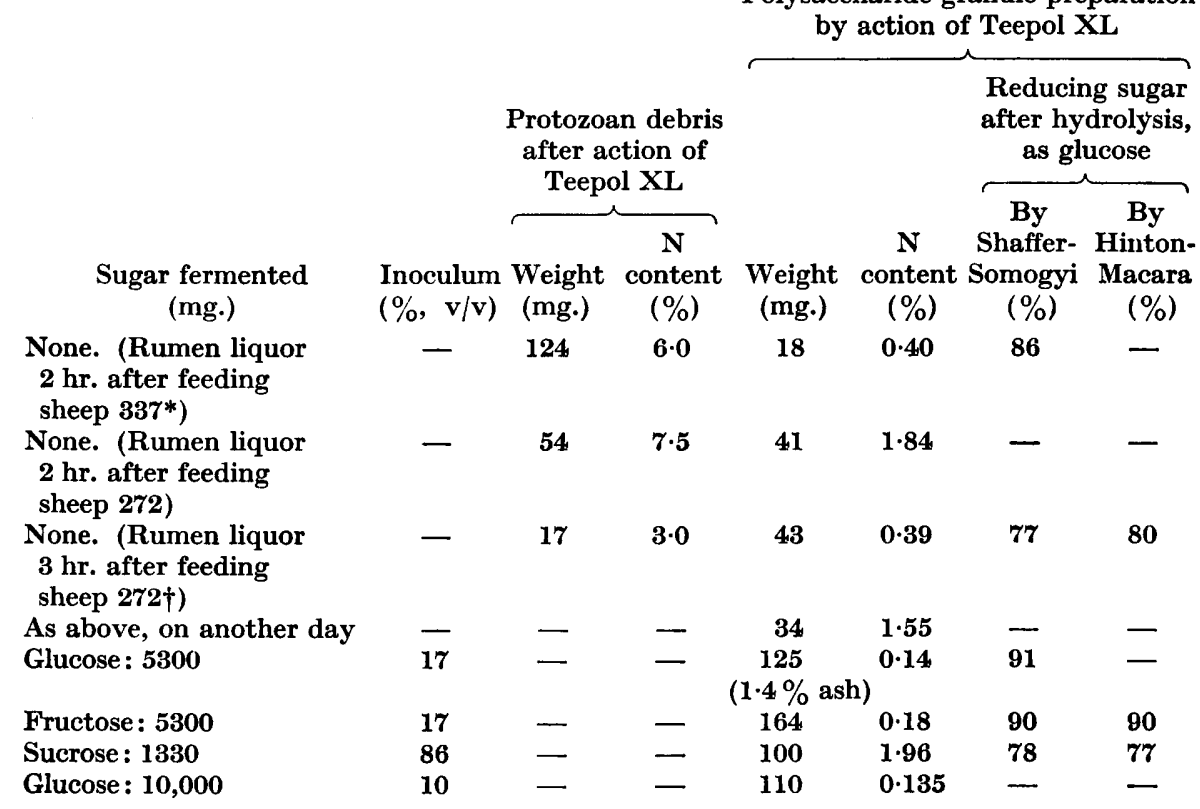

* Yielded $220 \mathrm{mg}$. of dried whole protozoa with nitrogen, $5 \cdot 1 \%$.

$\dagger$ This specimen of rumen liquor gave a much whiter bottom protozoan deposit than usual.

the respective dried preparations of whole protozoa so obtained are given in Table 2. It will be noted that the last preparation listed, which as mentioned above contained relatively more iodophilic oligotrichs than usual, had a much higher nitrogen content than the others. Attempts to burst the oligotrichs at a neutral $\mathrm{pH}$ by means of Teepol XL were unsuccessful.

Table 2. Nitrogen contents of dried whole protozoa obtained after fructose fermentation with small inocula of strained rumen liquor of various ages

Time elapsing between feeding of the sheep and removal of inoculum (hr.)

2
4
$6 \cdot 5$
9

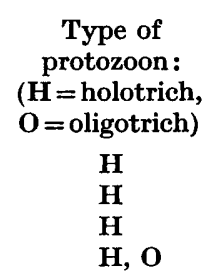

Washed and dried protozoa/100 $\mathrm{ml}$. of rumen-liquor inoculum

$\begin{array}{cc}\begin{array}{c}\text { Weight } \\ \text { (mg.) }\end{array} & \begin{array}{c}\text { N content } \\ (\%)\end{array} \\ 50 & 1 \cdot 61 \\ 60 & 1 \cdot 44 \\ 73 & 1 \cdot 13 \\ 27 & 3 \cdot 51\end{array}$

The immediate working-up of samples of the original inocula for polysaccharide granule preparations gave results which by no means paralleled the above. Only the first two, for instance, gave heavy white bottom layers on 
standing; the last $(9 \mathrm{hr}$.) inoculum gave hardly any iodophilic protozoa at all, and the relatively insignificant granule preparation made from the greyish green deposit yielded by it consisted chiefly of non-iodophilic bacteria, as its nitrogen content likewise showed. These results are summarized in Table 3. It will be seen that only the granule preparations from the 2 and $4 \mathrm{hr}$. inocula contained less than $2 \%$ nitrogen. Microscopic examination showed that at $6 \mathrm{hr}$. after feeding the iodophilic protozoa in the rumen had clearly lost the greater part of their polysaccharide granules, and that these had entirely disappeared after $9 \mathrm{hr}$; yet, as Table 2 shows, the holotrich protozoa themselves were still capable to some extent of resynthesizing polysaccharide granules in vitro if presented with a fermentable sugar, e.g. fructose.

\begin{tabular}{|c|c|c|c|}
\hline \multirow{2}{*}{$\begin{array}{l}\text { Time between } \\
\text { feeding of the } \\
\text { sheep and } \\
\text { removal of } \\
\text { rumen liquor } \\
\text { for protozoa } \\
\text { isolation } \\
\text { (hr.) }\end{array}$} & \multirow{2}{*}{$\begin{array}{c}\text { Type of } \\
\text { 'granule' } \\
(\mathbf{P}=\text { polysaccharide, } \\
\mathbf{B}=\text { bacteria })\end{array}$} & \multicolumn{2}{|c|}{$\begin{array}{l}\text { Washed and dried } \\
\text { granule preparations }\end{array}$} \\
\hline & & $\begin{array}{l}\text { Weight } \\
\text { (mg.) }\end{array}$ & $\begin{array}{c}\text { N content } \\
(\%)\end{array}$ \\
\hline 2 & $\mathbf{P}$ & 19 & $1 \cdot 01$ \\
\hline 4 & $\mathbf{P}$ & 32 & 1.74 \\
\hline 6.5 & $\mathbf{P}, \mathbf{B}$ & 18 & 3.73 \\
\hline 9 & B & 8 & $5 \cdot 84$ \\
\hline
\end{tabular}

Properties of the granule preparation

The dried granule preparations of low nitrogen content (see Table 1) could easily be resuspended in water to give a milky liquid which, when gradually heated, cleared at $\mathbf{7 0 - 8 0 ^ { \circ }}$ owing to the bursting of the granules. The now faintly turbid liquid was kept at $100^{\circ}$ for $5 \mathrm{~min}$., cooled, tested for reducing sugars (absent) and for bacteria by means of a wet preparation made with Loeffler's methylene blue (only a very few bacteria visible). It gave a purple colour with iodine reminiscent of that given by amylopectin, but quite unlike that usually given by glycogen. The chemical structure of this polysaccharide is now being investigated by Prof. E. L. Hirst and Dr E. G. V. Percival at Edinburgh.

There can be little doubt that the main simple sugar formed on hydrolysis, even when the preparation is derived from a fructose fermentation, is essentially glucose, since the reducing-sugar by alkaline-iodine oxidation was always equal to that determined by copper reduction (see Table 1). No hydrolysate gave the Seliwanoff reaction for fructose. Phenylglucosazone (m.p. and mixed m.p. $\mathbf{2 0 4}^{\circ}$ ) was in one instance prepared from the hydrolysate of granules obtained from a fructose fermentation.

\section{DISCUSSION}

Although the holotrich ciliates (e.g. Isotricha and Dasytricha) are not usually regarded as the most abundant type of protozoon in the rumen of sheep (Mangold (1929) gives about $10 \%$ of the total numbers for representatives of 
this group, as against $40 \%$ each for the oligotrichs Diplodinium and Entodinium) they are clearly the most active in depositing polysaccharide granules inside themselves when glucose, fructose or sucrose is present. The process is so rapid, and the extent of polysaccharide synthesis so considerable, that there can be little doubt that the protozoa themselves directly convert these simple sugars into iodophilic polysaccharide granules. It seems probable that a considerable fraction of the water-soluble and yeast-fermentable carbohydrate (presumably fructose) in the hay fed to the sheep in these experiments is stored in this form, at least temporarily, in rumen protozoa. A feed of $800 \mathrm{~g}$. hay would contain roughly $15 \mathrm{~g}$. of simple yeast-fermentable sugars. Assuming a total rumen-liquor content of $10 \mathrm{l}$. and that average samples are in fact withdrawn through the fistula, it can be calculated, from the figures given in Table 1 for sugar fermentations, that 2-3 hr. after feeding, as much as $4 \mathrm{~g}$. at least of protozoan polysaccharide granules have been synthesized and stored in holotrich ciliates alone. Owing to inevitable experimental losses the real amount stored must be considerably greater than this, even if no allowance be made for the lesser but obviously not inappreciable amount synthesized from simple sugars by oligotrich ciliates such as Diplodinium and Entodinium.

These granules cannot be micro-organisms since they contain far too little protein (less than $1 \%$ in the best preparation) and far too much carbohydrate (up to $90 \%$ ). Buchanan \& Fulmer (1928) listed eighteen species and strains of anaerobic and facultatively anaerobic bacteria with average nitrogen content of $9.5 \%$ (limits, $4 \cdot 0-14 \cdot 2 \%$ ), and pointed out that even yeasts rarely contain more than $60 \%$ of carbohydrate in their dried bodies. The synthesis of iodophilic polysaccharides by micro-organisms of the digestive tract is of course a well-known phenomenon, studied, for example, by Nasr \& Baker (1949) who, however, pointed out that this process is incompletely understood, particularly as concerns yeasts and protozoa.

The storage of protozoan polysaccharide granules in the rumen is only temporary since no trace of them could be obtained on working-up protozoa $9 \mathrm{hr}$. after feeding the sheep. It remains to be shown whether protozoa auto-ferment their polysaccharide store, or whether bacteria play a part in this process.

Of the three yeast-fermentable hexoses having a common enolic form, namely glucose, fructose and mannose, only the first two seem to be utilized in vitro by the holotrichous protozoa for making polysaccharide granules. An analogous example was observed by Kluyver \& Hoppenbrouwer (1931) who showed that Termobacterium mobile Lindner did not ferment mannose, although it readily fermented glucose and fructose, and, more slowly, sucrose. The fact that the glucose-containing disaccharides maltose and cellobiose are apparently not readily utilized by Isotricha and other holotrichs for iodophilic polysaccharide synthesis shows further how strictly limited are their synthetical powers.

I am indebted to Miss Frances Masson for much technical assistance, to Mr F. Baker for many helpful discussions, and to Mr P. J. Heald for the care of the animals and for the determination of yeast-fermentable carbohydrate in hay. 


\section{REFERENCES}

Buchanan, R. E. \& Fulmer, E. I. (1928). Physiology and Biochemistry of Bacteria. London: Baillière, Tindall and Cox.

Elsden, S. R. (1946). The fermentation of carbohydrates in the rumen of sheep. J. exp. Biol. 22, 51.

Elsden, S. R. \& Philuipson, A. T. (1948). Ruminant digestion. Ann. Rev. Biochem. $17,705$.

Hinton, C. L. \& Macara, T. (1924). Application of the iodometric method to the analysis of sugar products. Analyst, 49, 2.

Johnson, B. C., Hamilton, T. S., Robinson, W. B. \& Garey, J. C. (1944). On the mechanism of non-protein nitrogen utilization by ruminants. J. Anim. Sci. 3, 287.

KluYver, A. J. \& Hoppenbrouwer, W. J. (1931). Ein merkwürdiges Garungsbakterium Lindner's Termobakterium mobile. Arch. Mikrobiol. 2 (2), 245.

Mangold, E. (1929). Handbuch der Ernahrung und des Stoffwechsels der Landwirtschaftlichen Nutztiere. Berlin: J. Springer.

NASR, H. \& BAKER, F. (1949). Microbial synthesis of iodophile polysaccharide by a Clostridium from the caecum of the pig. Nature, Lond., 164, 745.

NeIsH, A. C. (1946). Analytical methods for the Bacillus subtilis fermentation. National Research Council of Canada, Rep. no. 46-8-3.

Tosic, J. (1949). Effect of small quantities of a yeast preparation on the recovery of appetite in sheep. Brit. J. Nutrit. 3, 234.

Wath, J. G. van Der \& Myburgh, S. J. (1941). Studies on the alimentary tract of Merino sheep in South Africa. VI. The role of infusoria in ruminant digestion with some remarks on ruminant bacteria. Onderstepoort J. vet. Sci. 17, 61 .

(Received 29 March 1950) 